\title{
Destructive lesions of vertebral bodies in ankylosing spondylitis
}

\author{
M. I. D. CAWLEY., T. M. CHALMERS., J. H. KELlgREN, AND J. BALL \\ Rheumatism Research Clinic, University of Manchester
}

This paper describes a clinico-pathological study of destructive lesions of the vertebrae in ankylosing spondylitis (AS), sometimes referred to as 'spondylodiscitis'.

\section{Review of the literature}

The first report of such lesions is attributable to Andersson (1937), who described sclerosis and destruction around the disc margins in lumbar and thoracic vertebrae in radiographs of two patients. The earliest significant clinical observations were made by Edström (1940). In a paper on the nature of AS, he referred to a male patient who, some years after the onset of the disease, developed severe pains in the back during a spell of unusually heavy work; a year later radiographs showed vertebral destruction around the T12/L1 disc. Tuberculosis was suspected but the lesion was not investigated pathologically. In retrospect this clinical sequence is in some respects exemplary, yet it receives little emphasis in subsequent reports. Indeed, the purely clinical aspects of patients with destructive lesions are not well documented in the literature and have not been made the subject of a formal study. In 1951 the lesions were again briefly mentioned by Guest and Jacobson (1951) and Forestier, Jacqueline, and Rotès-Quérol (1951: trans. 1956), the latter authors having encountered two cases in their review of 200 patients with AS. The following year Romanus and Ydén (1952) described the superficial, short-lived, erosion of the anterior and antero-lateral surface of the vertebral rim which they called 'anterior spondylitis'. Their systematic radiological studies were prompted by their having encountered patients with AS and severe destructive lesions of vertebral bodies; having discovered minor vertebral erosions close to discs (anterior spondylitis) in the early stages of AS, they speculated that severe destructive lesions might be exceptional extensions of the primary inflammatory phase of the disease.

Since recent pathological studies (Ball, 1971) indicate that anterior spondylitis, as defined above, is probably the precursor of the characteristic ossification of the annulus (Fig. 1), it seems important Accepted for publication January 26, 1972 at the outset to distinguish this lesion from those generally regarded as destructive lesions-a point to which we will return later.

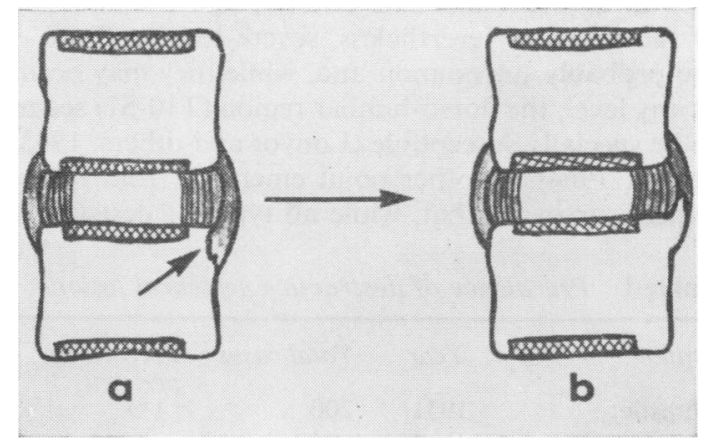

FIG. 1 Anterior spondylitis (a) erosion of attachment of outer annulus (b) healed erosion producing syndesmophyte

Jacqueline (1956) classified destructive lesions into two groups according to whether they occurred in the early stage of spinal ankylosis or in spines with advanced ossification, and he pointed out that in the latter severe lesions might be provoked by trauma, a clear history of which was given by two of his three patients in this group. In this connection it may be noted that Wilkinson and Bywaters (1958), in the first British contribution to the subject, described the radiographic appearance in their patient with a spontaneous severe destructive lesion as a crush fracture.

The clinical presentation of certain destructive lesions late in the course of the disease was again emphasized by Wholey, Pugh, and Bickel (1960), whose ten patients had all had AS for at least 10 years before the lesions were discovered.

During the last decade several radiological studies (Seaman and Wells, 1961 ; Louyot, Gaucher, Mathieu, and Miquel, 1963; Coste, Delbarre, Cayla, Massias, and Beasley, 1963; Strěda, 1964; Jacqueline, 1965; Serre, Simon, and Claustre, 1965; Schulitz, 1968, 1969; Dihlmann, 1968; Rivelis and Freiberger, 1969; Daneo and Di Vittorio, 1970) have established that, whereas destructive lesions invariably affect vertebral 
bodies close to a disc, the extent of involvement varies considerably. Most investigators have recognized two main types of lesion, one localized and the other involving more or less the whole of the disc-bone border.

These may be conveniently (and perhaps significantly) classified into three main groups according to whether the lesion involves the discal surface of the vertebral $\operatorname{rim}$ (Types $a$ and $b$ ), the cartilaginous part of the vertebral end-plate (Types $c$ and $d$ ), or both (Type $e$ ) (Fig. 2).

Radiological estimates of the prevalence of destructive lesions have varied between 1 and 28 per cent. (Table I). Estimates of the prevalence and distribution of lesions have probably been influenced by the method used, the extent of spinal survey undertaken, lack of agreed diagnostic criteria, and the duration of the disease. Nevertheless, severe lesions (Type $e$ ) are probably uncommon and, while they may occur at any level, the dorso-lumbar region (T10-S1) seems to be specially susceptible (Louyot and others, 1963; Strěda, 1964). Another point emerging from radiological surveys is that, while all types of destructive

Table I Prevalence of destructive vertebral lesions

\begin{tabular}{|c|c|c|c|}
\hline Author & Year & Total cases & Prevalence \\
\hline Forestier & 1951 & 200 & $\begin{array}{r}\text { perc } \\
1.0\end{array}$ \\
\hline Coste and others & 1963 & 171 & $4 \cdot 7$ \\
\hline Strěda & 1964 & 250 & $15 \cdot 2$ \\
\hline Jacqueline* & 1965 & $\overline{165}$ & $28 \cdot \overline{5}$ \\
\hline Serre and others & 1965 & 150 & $10 \cdot 0$ \\
\hline Hackenbroch & 1967 & 255 & $2 \cdot 7$ \\
\hline Dihlmann & $\begin{array}{l}1968 \\
1968\end{array}$ & $\begin{array}{r}549 \\
50\end{array}$ & $\begin{array}{r}2 \cdot 7 \\
18 \cdot 0\end{array}$ \\
\hline Schulitz & 1969 & 371 & $3 \cdot 0$ \\
\hline
\end{tabular}

* We have excluded his Type I lesions which appear to represent anterior spondylitis.

t Tomography. lesion may be seen late in the course of the disease Type $e$ lesions are rarely seen in unankylosed spines.

Published data on the pathology of destructive lesions is limited to seven reports of biopsies of ten lesions. In none was there any histological evidence of bacterial infection and bacterial cultures were negative in the six cases tested. The first report was that of Wholey and others (1960), who described their findings in two patients: one showed 'changes consistent with an inflammatory reaction', the other 'findings consistent with a chronic inflammation'. Coste and others (1963) presented a more detailed account of the pathology in one of their cases. They found replacement of bone by fibrous tissue containing new bone and haemosiderin deposits, and oedematous marrow containing perivascular collections of lymphocytes and plasma cells. They concluded that the lesions had an inflammatory component but left the question of pathogenesis open. Serre and others (1965) briefly reported finding 'a non-specific granulo-histiocytic infiltrate', and Hackenbroch (1967) wrote of a 'non-specific inflammation of moderate or minimal intensity with occasional round cell infiltration'. This evidence has apparently been accepted by some as supporting a primary inflammatory origin for the destructive lesions, but the consideration of three more recen reports casts some doubt on this view.

(1) Hansen, Taylor, Honet, and Lewis (1967) described a patient with AS of 20 years' duration who felt pain and a snapping sensation in the back after stepping off a kerb. The pain, though not severe, persisted, and 7 months later radiographs showed a Type $e$ lesion at the T12/L1 disc and a biopsy revealed 'non-specific granulomatous inflammatory tissue'. A bone graft was inserted and there were no further symptoms until 5 years later when, rising from bed, he felt a 'pop' in his back followed by severe pain. The following day radiographs showed a fracture dislocation at $T 11 / 12$. The question raised by this case (though not mentioned by the authors) is whether the first destructive lesion (at T12/L1) was the late result of a similar but less severe fracture.

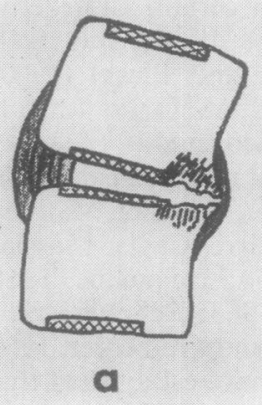

FIG. 2 Types of destructive lesions: lateral view, anterior to right.
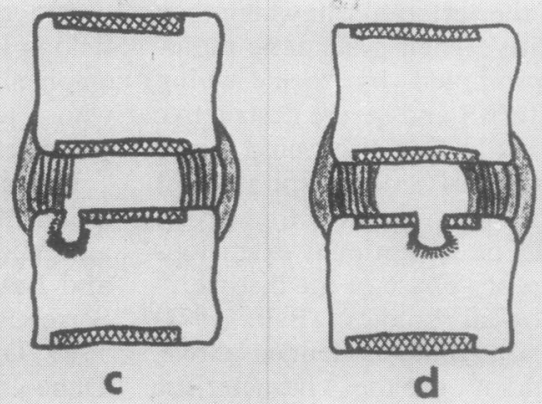

cartilage plate

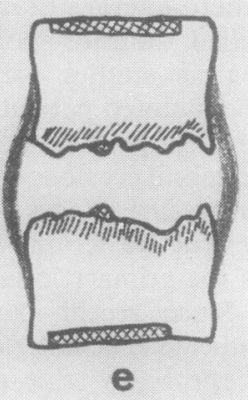

osteosclerosis 


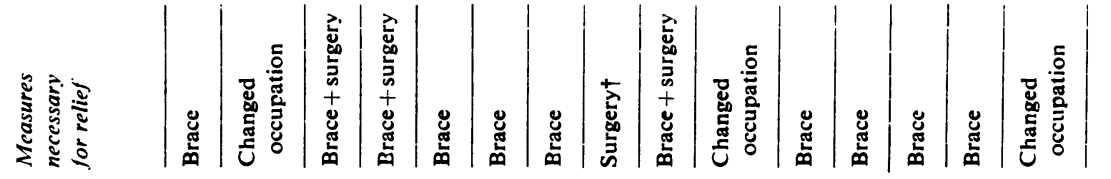
(1)

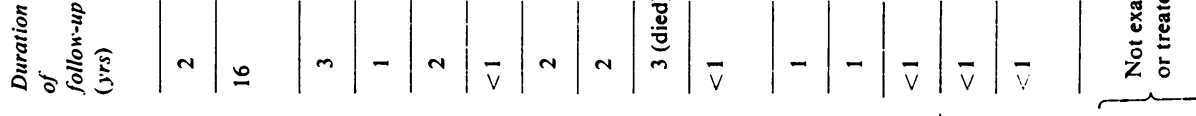

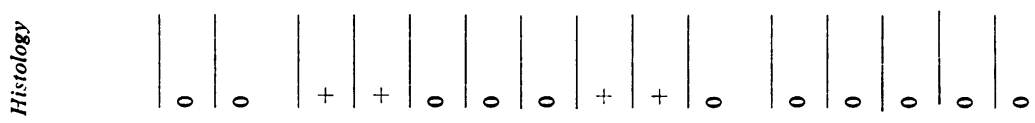

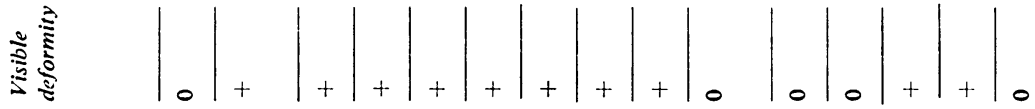

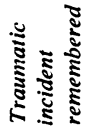<smiles>C1C2CC1C2</smiles>

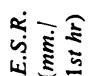

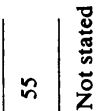

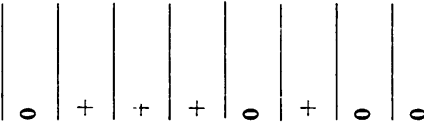

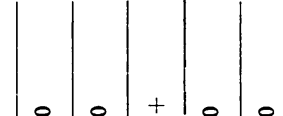

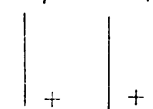

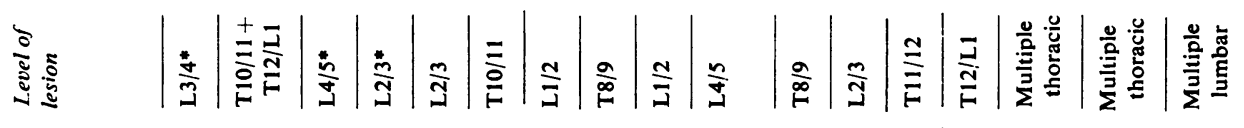

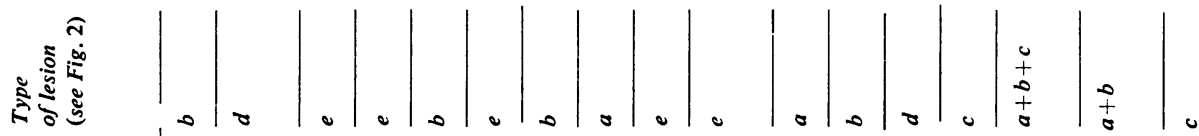

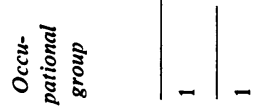
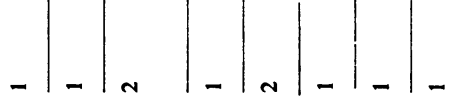

$\bar{z}=\overline{2}$

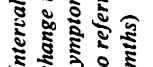

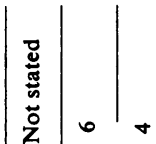

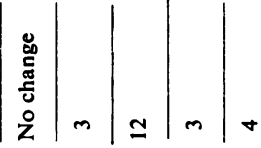

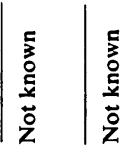

施

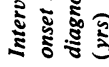

\section{.}

-

$\ln$

\section{-}

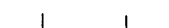

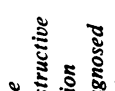

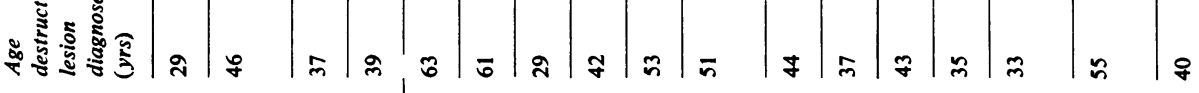

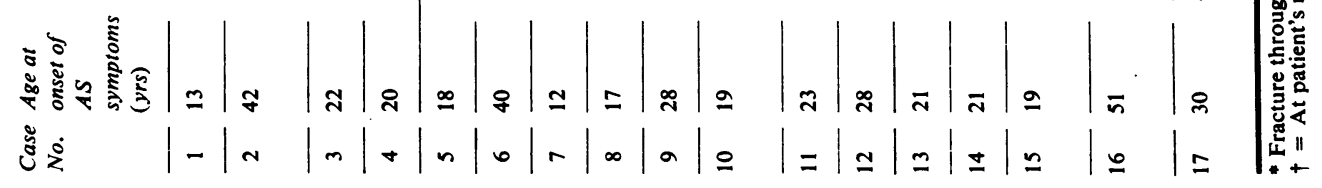


(2) Kanefield, Mullins, Freehafer, Furey, Horenstein, and Chamberlin (1969) described three patients with severe lesions in whom tissue obtained at biopsy was described respectively as "non-specific granulation tissue', 'non-specific chronic inflammation', and 'fibrous tissue ... with new-bone ... fibroblasts, and fibrinoid degeneration and macrophages'. In two of these cases there was evidence in radiographs taken at the time of onset of localized back pain that the destructive changes seen later had originated in a non-dislocated fracture of an ankylosed segment. The authors concluded that the 'mechanism of granuloma formation might be traumatic'.

(3) In the report of Rivelis and Freiberger (1969), two additional points emerged. In their Case 1, tissue from the posterior spinal joint revealed reactive fibroblastic tissue, bone resorption, and reactive bone deposition, and tissue from the corresponding disc showed proliferative connective tissue, microscopic sequestra, and reactive new-bone formation. These findings were considered to represent a pseudarthrosis. Secondly, in their Cases 2 and 3, it was asserted that a localized destructive lesion in the anterior part of the disc had occurred in the only unankylosed segment in the lumbar region. They concluded that the destructive lesions in their cases might be explained by excessive forces imposed on an isolated mobile segment in a rigid spine.

The reports of Kanefield and others and of Rivelis and Freiberger seem to show that a destructive lesion may be the late result of a stress fracture through an ankylosed segment or may be produced by abnormal stress on a mobile segment lying between ankylosed regions.

Since there is a paucity of clinical information and views about the pathogenesis of destructive lesions are conflicting, it seemed worth while to review our patients, paying particular attention to the clinical and pathological aspects. Our clinical, radiological, and pathological findings are consistent with a traumatic aetiology.

\section{Material and methods}

We have studied seventeen male patients with established AS, of whom fifteen presented to us with clinical and radiological features of destructive lesions. Ten have been followed up for 1 to 3 years and one for 16 years. Tissue has been obtained at operation from four of these 15 patients, and post mortem from two others whom we did not have the opportunity to examine clinically. Tissue from thirteen un-united fractures in patients without AS has also been studied for comparison.

\section{Clinical features}

The important data on all the patients studied are summarized in Table II (p. 347). The ages of our seventeen cases, all male, ranged from 29 to 63 years at the time radiographs disclosing destructive lesions were taken. The duration of AS at that time ranged from 4 to 45 years. All extensive (Type $e$ ) lesions occurred in patients with a disease duration of 15 years or more. Other types were seen in both early and late stages.

The occupations of our patients were of interest by comparison with those of 100 unselected male patients with AS. Table III shows that, at the time of the onset of back pain (as distinct from the onset of AS), 67 per cent. of patients with destructive lesions were employed in heavy manual work as compared with 28 per cent. of the unselected group.

Table III Occupational history

\begin{tabular}{|c|c|c|}
\hline Occupation & Present series & Unselected serie \\
\hline $\begin{array}{l}\text { Manual } \\
\text { Light manual } \\
\text { Sedentary }\end{array}$ & $\begin{array}{r}10 \\
5 \\
0\end{array}$ & $\begin{array}{l}28 \\
37 \\
35\end{array}$ \\
\hline Total & 15 & 100 \\
\hline
\end{tabular}

\section{History}

In fourteen of the fifteen cases seen clinically we were impressed by a characteristic change in symptoms which had occurred 2 to 12 months before referral. Usually, backache in AS, as is well recognized, is diffuse in distribuo tion, tends to be increased by inactivity, and is relieved bo mobilization. The patients in this study developed, ofter quite suddenly, a more localized pain, usually in the are of distribution from a single spinal segment. Secondly, the pain was exacerbated by physical activity, especially heavy work, and was relieved by rest. In only three of our patients was there any evidence of concurrent exacerbation of disease activity. Four patients related the onset of their new symptoms to a specific traumatic incident of a minor nature, including a light blow on the lumbar region in one case, and sitting up suddenly in bed in another. One patient (Case 4) was referred to us because the pain, which had been attributed to a relapse of AS, had failed to respond to radiotherapy. Another (Case 13) had undergone full urological investigation for severe loin pain, with negative result, before referral.

\section{Examination}

In addition to the usual signs of AS, local tenderness on percussion or palpation at the level of the destructive lesion was observed in thirteen patients. In the two remaining patients these signs were absent, and in the two post mortem cases they had not been recorded. In eleven patients there was a localized visible or palpable spinal deformity or gibbus. In all patients movement of the affected segment reproduced the localized pain. In patients with spinal ankylosis, this was most convincingly demonstrated by pressure on the adjacent part of the spine with the patient prone. It is important to differentiate this type of local pain from a more superficial tenderness which is due to the characteristic ligamentous attachment lesions which may occur over the spinous processes.

There was no evidence that iritis, carditis, or other nonskeletal manifestations occurred more commonly in patients with destructive lesions than in those without One patient (Case 12) had had pulmonary tuberculosis 
one year before the onset of AS and had been successfully treated by chemotherapy and upper lobe resection. There was no evidence of recurrence of tuberculosis at the time of the destructive lesion some 12 years later.

The erythrocyte sedimentation rate (E.S.R. Westergren) ranged from 23 to $115 \mathrm{~mm}$./1st $\mathrm{hr}$ when the destructive lesion was diagnosed, but there was no evidence that this index of disease activity had increased with the development of the destructive lesion.

Nine patients (Cases 3, 4, 5, 6, 7, 10, 11, 14, 15) had previously had radiotherapy to the spine, including the level at which the destructive lesion was found; of these, four had extensive lesions and five minor lesions. Only one patient (Case 5) had received corticosteroids (in low intermittent dosage for 4 years) before the discovery of the destructive lesion.

\section{Radiography}

The various radiological changes in the vertebral bodies conform to those described in the literature (Fig. 2). In addition we have observed fractures of the neural arch in association with both localized and extensive lesions. With the exception of Case 6, all the lesions studied were situated in the lower half

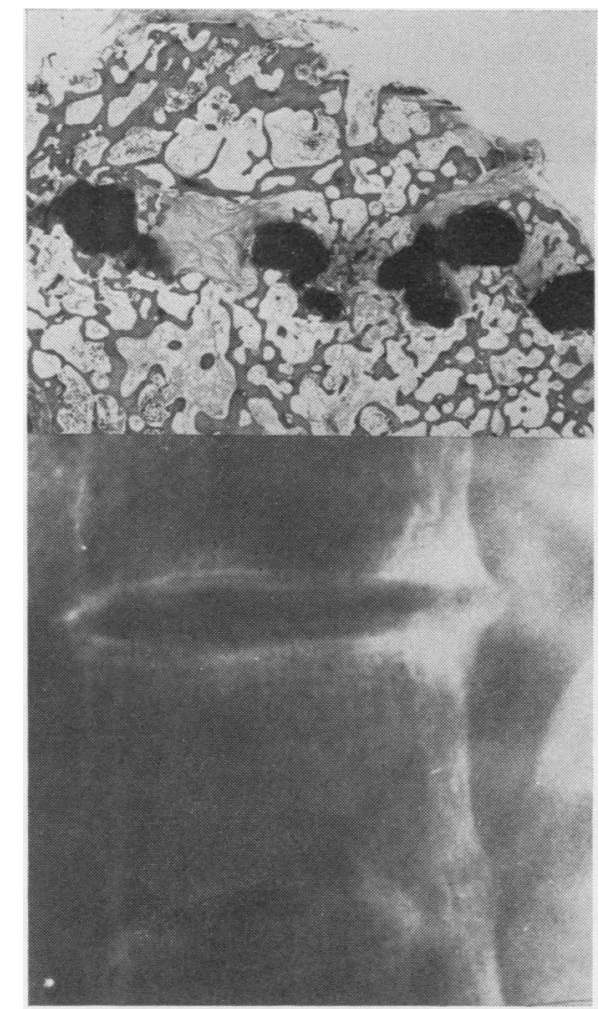

FIG. 3 Case 8. Type a lesion. X-ray shows opacity around anterior part of narrowed T8/9 disc. Section (above) shows disc replaced by fibrous tissue and cartilaginous nodules of the thoracic spine or in the lumbar spine (Table II).

\section{LOCALIZED LESIONS}

\section{Thoracic spine}

Lesions (Types $a$ and $b$ ) were found predominantly anteriorly in kyphotic spines. They varied from thinning of the anterior third of a single disc with irregularity and sclerosis of neighbouring bone (Figs 3 and 4) to local defects involving all but the outermost part of the anterior vertebral rim on either side of several discs (Figs 5 and 6, overleaf). In the single case with more severe thoracic lesions (Case 16), ossification of the same area of the discs was present in neighbouring vertebrae (Fig. 5).

\section{Lumbar spine}

Localized lesions (Types $b, c$, and $d$ ) at the disc-bone border were seen in anterior, antero-lateral, posterolateral, and posterior situations. Anterior or posterior lesions were easily recognized in plain lateral radiographs. The detection of lesions at other sites required tomography or, in post mortem specimens, radiographs of slab sections. The lesions (Types $b, c$, and $d$ ) typically presented as a saucer- or cup-shaped defect at the disc-bone border delineated by a zone of vertebral density (Figs 7, 8, 9, overleaf). In lesions involving the discal surface of the vertebral rim (Type $b$ ), it was noted that the outermost part of the rim and the anterior vertebral surface just below the rim edge appeared to be intact. Occasionally a Type $b$ lesion was bordered externally by an incomplete syndesmophyte. In one instance (Case 1), a Type $b$ lesion was associated with apparently ankylosed apophyseal joints and a fracture of the neural arch (Fig. 9). It

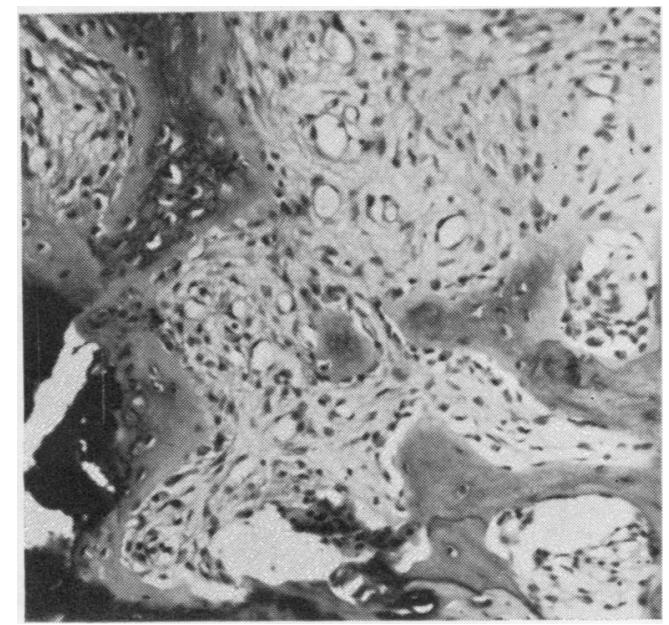

FIG. 4 Case 8. Detail of Fig. 3, showing reactive bone, fibrous tissue, and cartilage. Haematoxylin and eosin $\times 120$ 


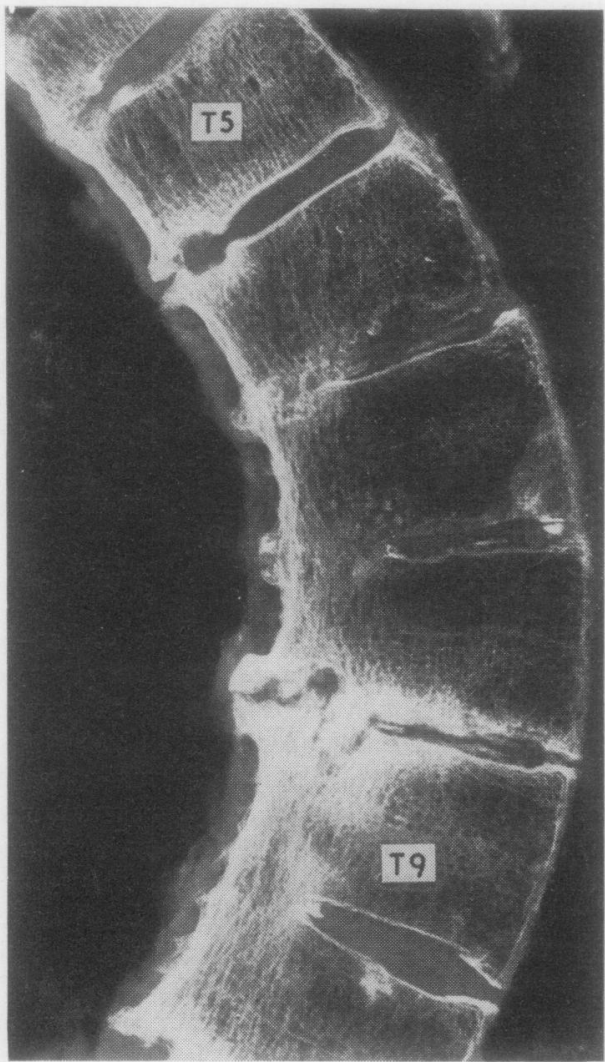

FIG. 5 Case 16. Type b lesion. Slab post mortem radiograph, showing punched-out defect of anterior vertebral rim of $\mathrm{T} 5 / 6$ and 8/9. Corresponding area is ossified in $\mathrm{T} 6 / 7$, $\mathrm{T} 7 / 8$, and $\mathrm{T} 9 / 10$

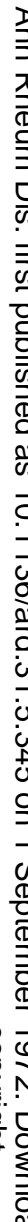

FIG. 7 Case 13. Type b lesion. Tomogram, showing saucer-shaped defect (arrow) in lower anterior rim of $\mathrm{T} 11$ not apparent in plain radiograph

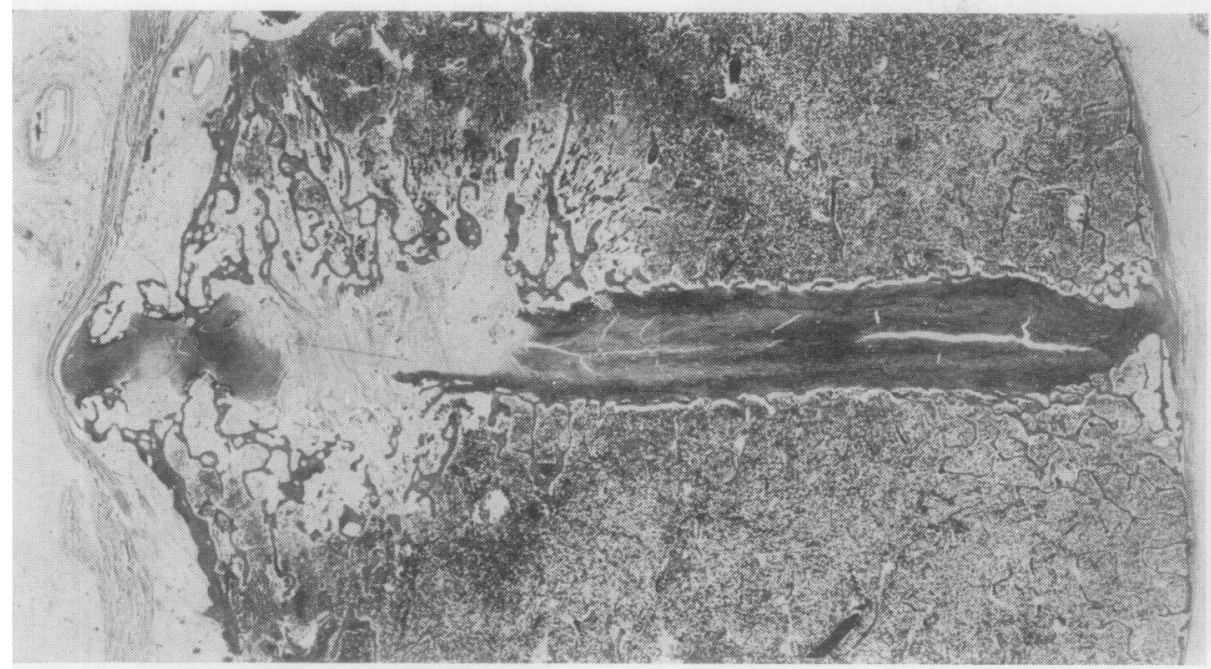

FIG. 6 Case 16. Histological section of T5/6 disc shown in Fig. 5. All but the outer edge of the rim and the intervening disc are replaced by vascular fibrous tissue. Lesion delineated by thick bone trabeculae. No anterior spondylitis. Haematoxylin and eosin $\times 4$ 


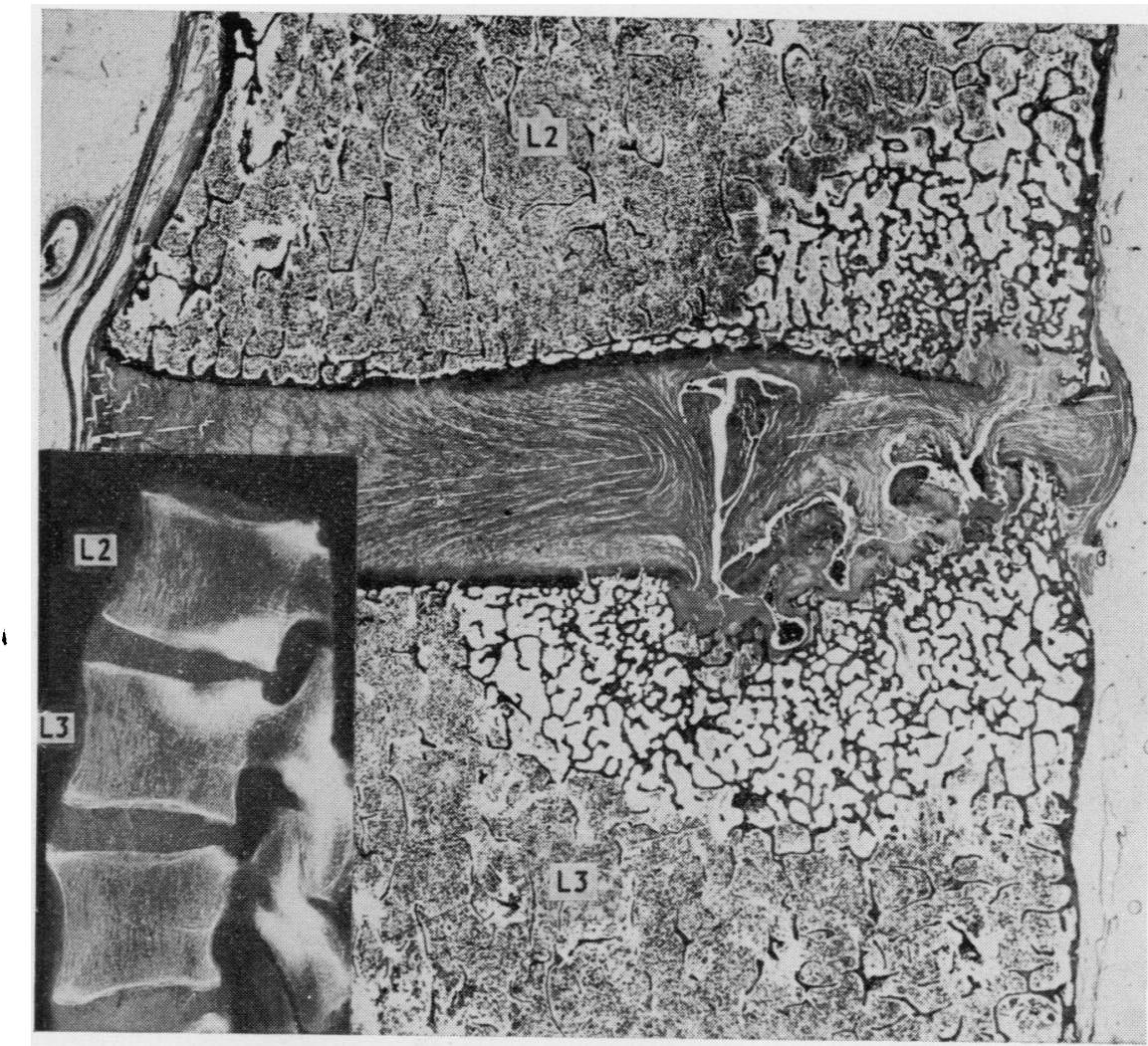

FIG. 8 Case 17. Type c lesion L2/3 disc. Section shows discal hernia through upper cartilage plate of $\mathrm{L} 3$, surrounded by cancellous bone enclosing oedematous hypocellular marrow. Defect in rim of L2 occupied by avascular disc-like tissue. Haematoxylin and eosin $\times 3$ INSET Post-mortem radiograph of $\mathrm{L} 2 / 3$ disc

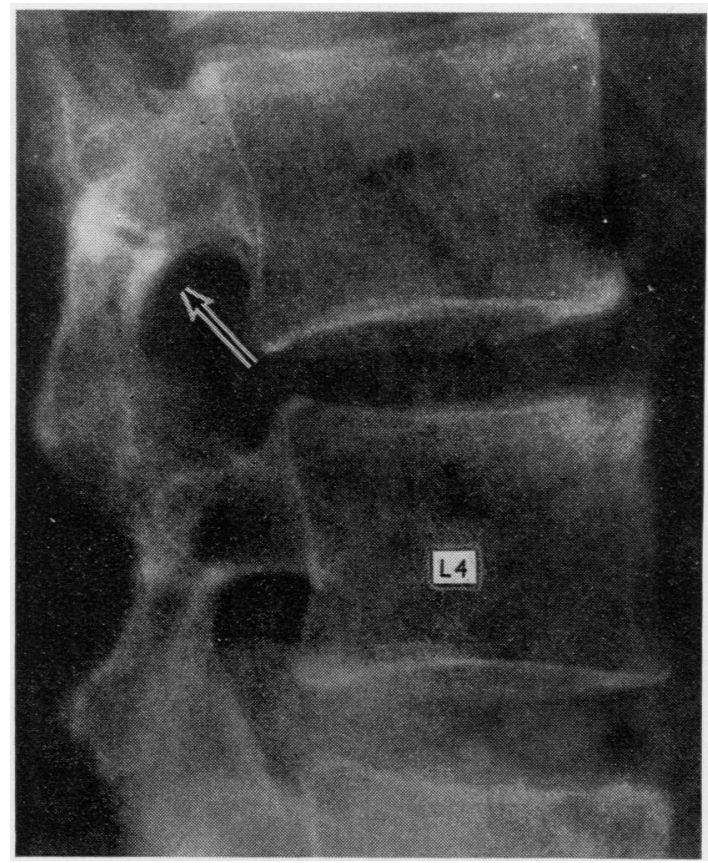

FIG. 9 Case 1. Type b lesion in upper anterior rim of L4. Apophyseal joints ankylosed. There appears to be a fracture in the neural arch (arrow) was also evident from post mortem studies (Fig. 8) that Type $c$ lesions involving the cartilaginous part of the end-plate may occur in an unankylosed lumbar spine.

\section{EXTENSIVE LESIONS}

These (Type $e$ ) typically involved a single segment, above and below which the spine showed advanced ankylosis. The affected segment was, in some instances, demonstrably mobile. Dislocation, lateral or sagittal usually of a relatively minor degree, was observed in some cases. Characteristically there was irregular destruction of the central and peripheral parts of the disc-bone border extending for a few millimetres into the vertebral body and bordered by a narrow zone of radio-opacity. Both the upper and lower surfaces were commonly involved, although usually one was more severely affected than the other. In two of the five patients with this type of lesion there was a fracture through the corresponding neural arch (Figs 10 and 11, overleaf).

\section{Pathology}

LOCALIZED LESIONS

Type a (Case 8) A clinical radiograph and the histological appearances of the biopsy are shown in Figs 3 and 4. Two cancellous bone fragments (the bone above and 
F IG. 10 Case 3. Type e lesion at L4/5 with gross destruction. Apophyseal joints ankylosed. Arrow points to fracture in neural arch

below the disc) are joined by fibrocartilaginous nodules and fibrous tissue. In the latter (Fig. 4) new-bone deposition can be seen. Scanty lymphocytes and plasma cells are present in the oedematous marrow in the cancellous bone. The overall appearance resembles an incompletely healed fracture.

Type $b$ (Case 16) Serial slab sections (Fig. 5) of this thoracic spine show destructive lesions predominantly involving anterior vertebral rims at T5/6, 8/9, and 11/12. The most severe lesion (T8/9) lies between ankylosed regions, T6-8 above and $\mathrm{T} 9 / 10$ below. The ankylosis of the vertebral bodies in these regions is similar to that seen in senile kyphosis. Each destructive lesion is associated anteriorly with small beak-like osteophytes. Histologically (Fig. 6), all the anterior lesions show focal replacement of the disc and disc-bone border by vascular fibrous tissue containing groups of haemosiderin-laden phagocytes and very scanty lymphocytes and plasma cells - changes resembling those described by Schmorl and Junghanns (1959) in the early stages of senile kyphosis. The narrow zone of radiodensity delimiting the lesions consists of thickened trabeculae of mainly lamellar bone, the marow spaces in which show recent haemorrhage. The V-shaped translucency in the lesion at T8/9 is occupied by cartilaginous and fibrous tissue, the latter containing reactive new bone. The radiodensity occupying the Vshaped area consists of trabeculae of mainly lamellar bone. At the edges of the $\mathrm{V}$-shaped area there are foci of crumpled bone-clear evidence of trauma. There is no

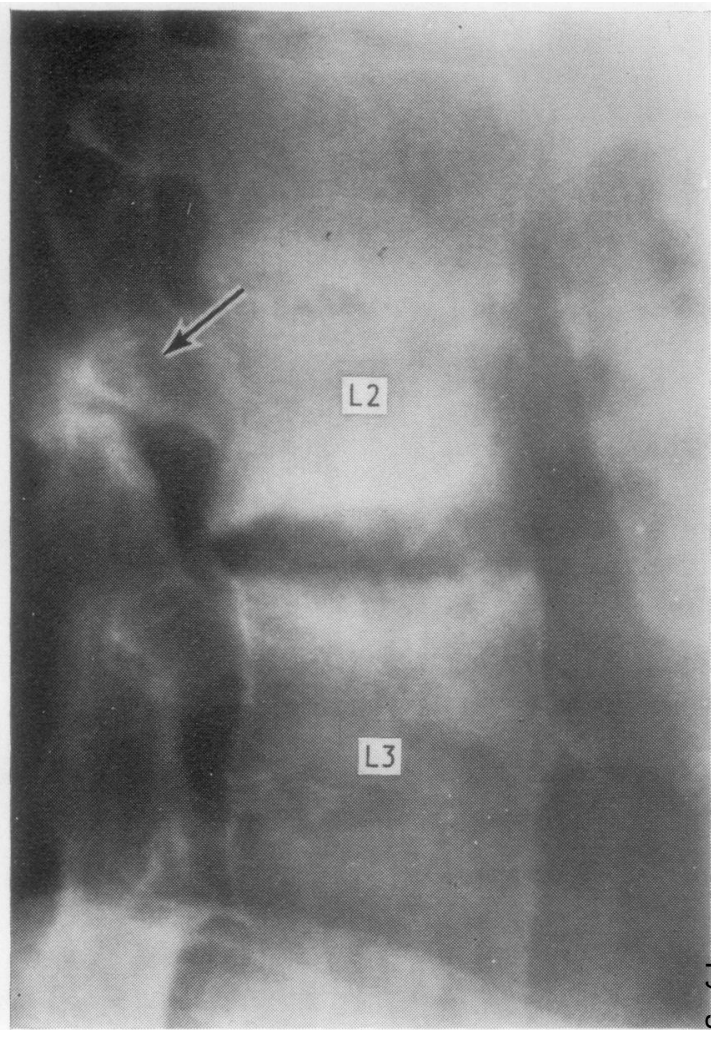

FIG. 11 Case 4. Type e lesions at L2/3 with posterior displacement. Apophyseal joints ankylosed. Arrow points to fracture through neural arch. Discs above and below lesion ankylosed

evidence of anterior spondylitis or aseptic necrosis. The central and posterior parts of the vertebral bodies are porotic. This process has produced thinning and focal loss of the subchondral bony end-plate and of the bony support of the vertebral rim (Fig. 12a, opposite).

Type c (Case 17) The lumbar spine in this patient, as judged by radiographs and histological sections of discs and posterior spinal joints, was mobile and lacked syndesmophytes (Fig. 8). Radiographs of slab sections reveal destructive lesions (not easily recognized in radiographs of the whole specimen) in the left postero-lateral part of the $\mathrm{L} 2 / 3$ disc and the right lateral part of the L5/S1 disc. Histologically the lesions are virtually identical. At the L2/3 level (Fig. 8), there are two defects in the cartilaginous plate of L3. Here avascular disc tissue can be seen to stream into the vertebral body where it merges with a narrow zone of reactive fibrocartilage attached to the surrounding bone. At the edges of the lesion there is some reactive bone; but the sclerotic zone delimiting the lesion consists mainly of lamellar bone trabeculae enclosing hypocellular oedematous marrow. Pathologically this type of bone sclerosis suggests persistent excessive pressure. Opposite to this lesion in L3 there is a similar defect in the lower border of L2 at the junction of the cartilage plate and vertebral rim. The lumbar vertebral bodies are generally porotic and as in 

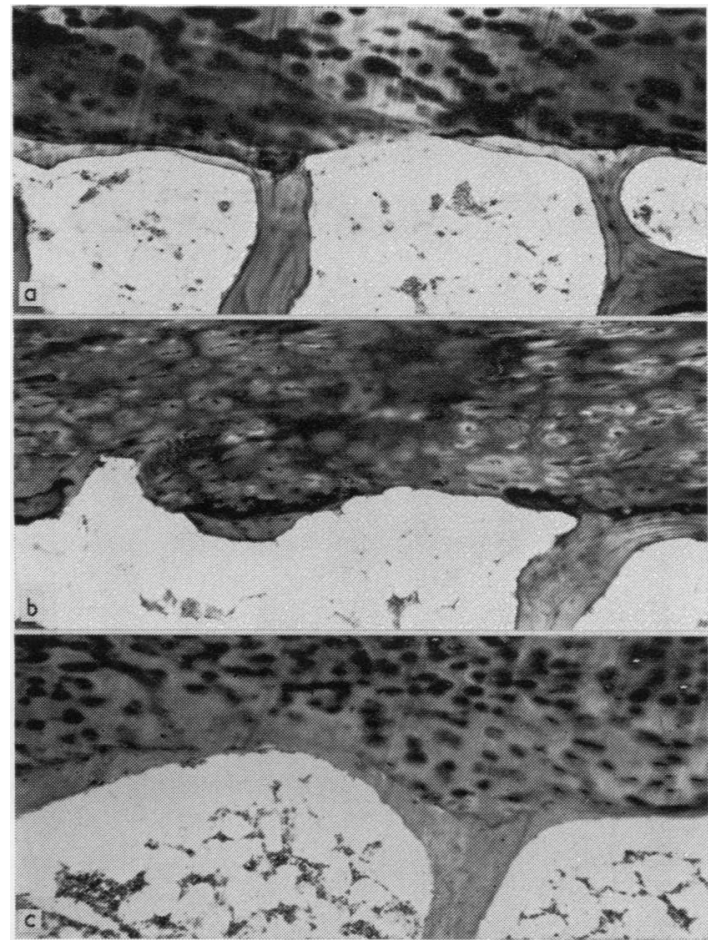

FIG. 12 (a) Case 16. Osteoporotic thinning and focal loss of subchondral bone plate in ankylosed spine

(b) Case 17 as for (a) in an unankylosed spine.

(c) Non-spondylitic control case of osteoporosis. Haematoxylin and eosin $\times 95$

Case 16 there is osteoporotic thinning and osteoporotic focal loss of the bony end-plate (Fig. 12b). There is no evidence of anterior spondylitis or aseptic necrosis.

EXTENSIVE LESIONS

Type $e$ (Cases 3, 4, and 9) The biopsy specimen included the disc-bone border and adjacent vertebral bone. All are similar histologically and may be described as a group. In none is there any evidence of bacterial infection, tuberculous or otherwise; nor is there evidence of aseptic necrosis or radiation damage to bone. The lesion (Fig. 13) can be divided into three merging zones, $a-c$, moving from the disc towards the vertebral bone. Zone $a$ (Fig. 14) consists of disc tissue in which the most notable change is the presence of capillary congeries and microscopic foci of eosinophilic degeneration which, incidentally are quite unlike the formations seen in a rheumatoid nodule. There are no inflammatory cells in zone $a$.

Zone $b$ (Figs 15, 16, 17) includes the disc-bone border. Here the vertebral bony end-plate and discal cartilage are invaded and largely or completely replaced by immature connective tissue composed of proliferating capillaries and fibroblasts (granulation tissue) in which inflammatory cells are inconspicuous or absent. There is both recent and

FIG. 14 Case 9. Type e lesion.Zone a Capillaries invade disc remnant showing eosinophilic degeneration (upper right) Haematoxylin and eosin $\times 95$

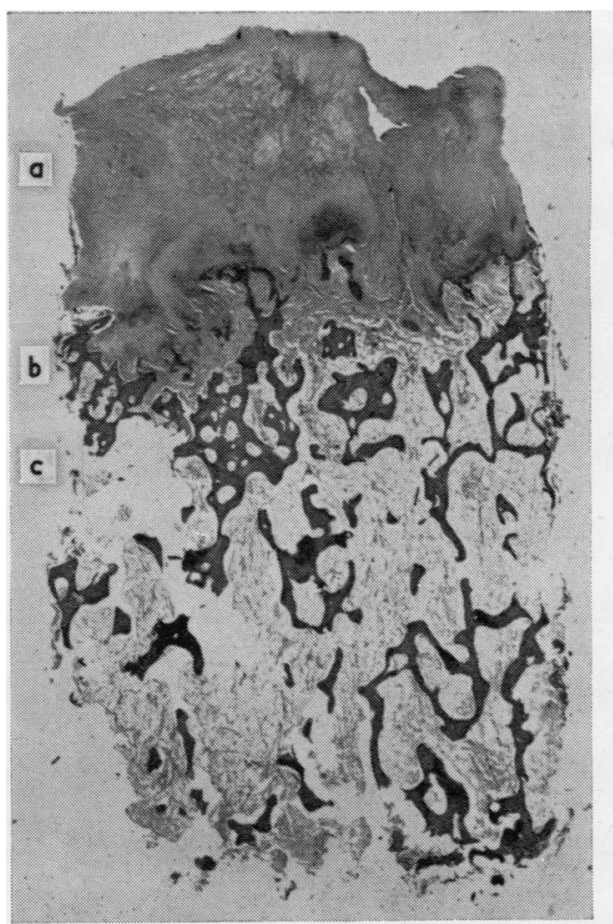

FIG. 13 Case 9. Type e lesion. Zone a Disc remnant; Zone b Erosion at disc-bone border; Zone c Osteosclerosis. Haematoxylin and eosin $\times 6$

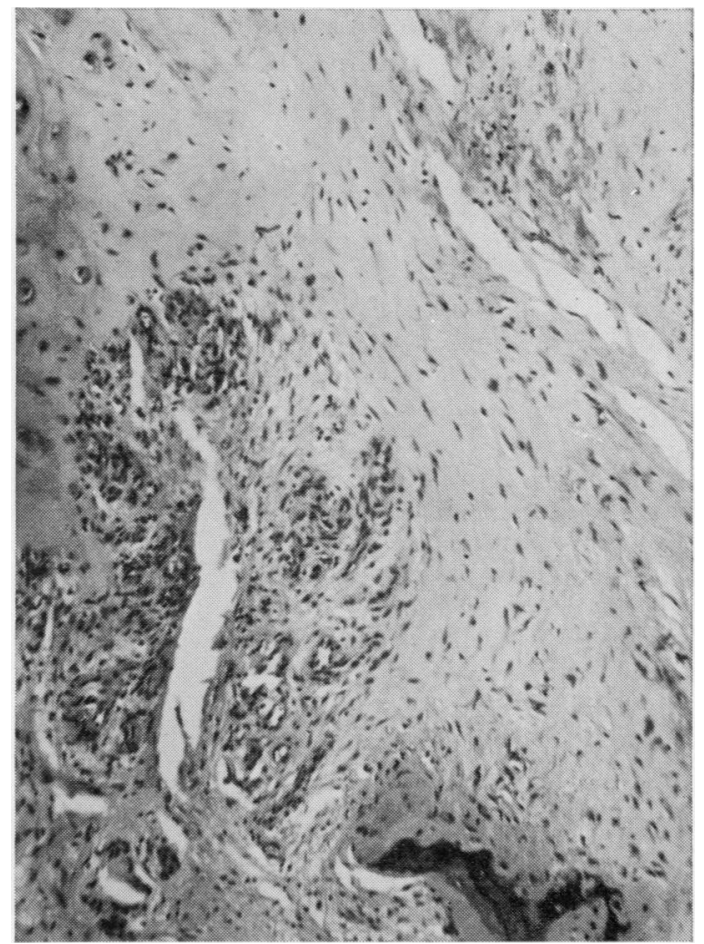




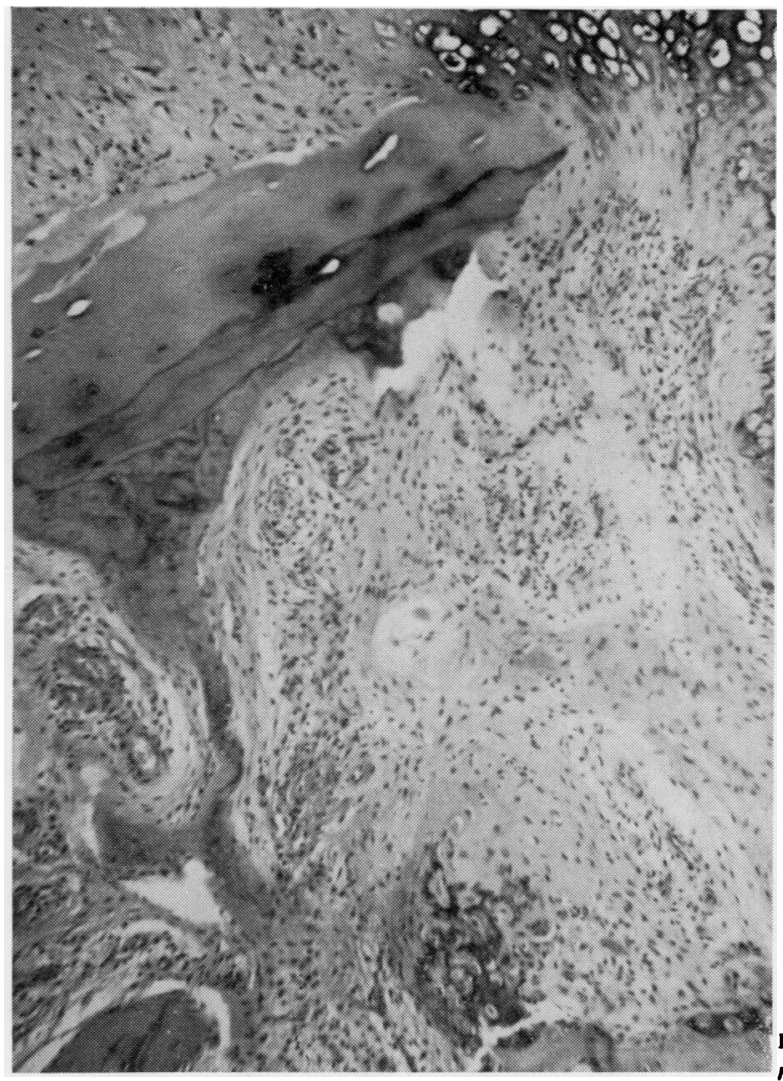

FIG.15 Case 9. Type e lesion. Zone b Remnant of original cartilaginous end-plate eroded by granulation tissue. Inflammatory cells very scanty. Reactive fibrocartilage below centre and upper right. Haematoxylin and eosin $\times 95$
FIG. 17 Case 3. Type e lesion. Zone b Irregular bony fragments embedded in vascular fibrous tissue replacing vertebral end-plate. No inflammatory cell infiltration. Haematoxylin and eosin $\times 95$

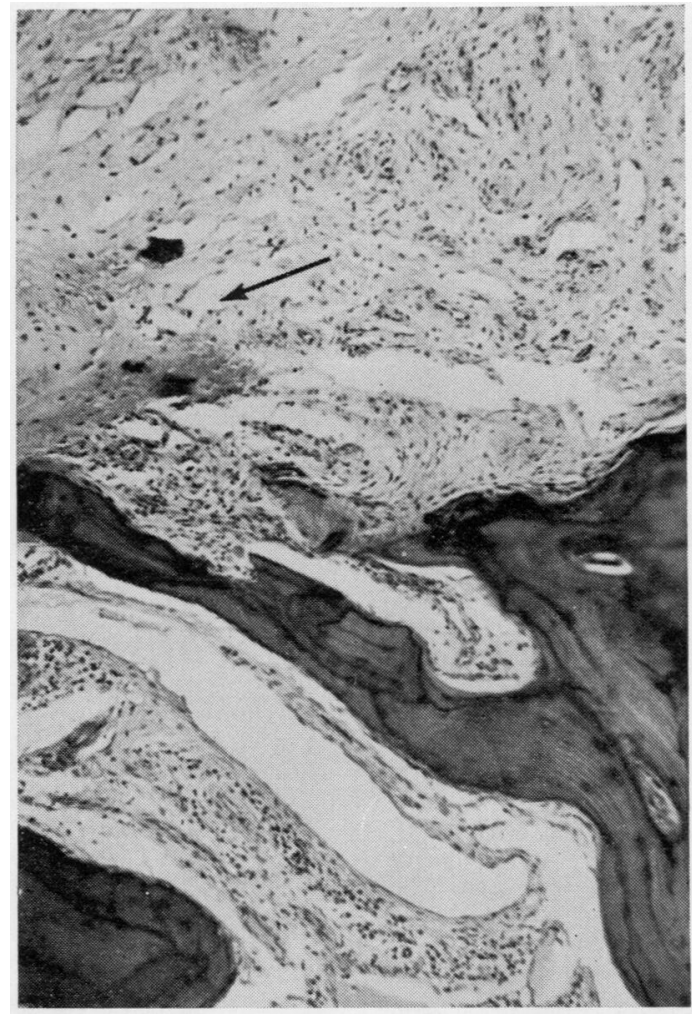

FIG. 16 Case 3. Type e lesion.Zone b Disc-bone border replaced by vascular fibrous tissue in which fibrocartilage has formed (arrow). Perisinusoidal lymphocytes and plasma cells in subjacent marrow. Haematoxylin and eosin $\times 95$

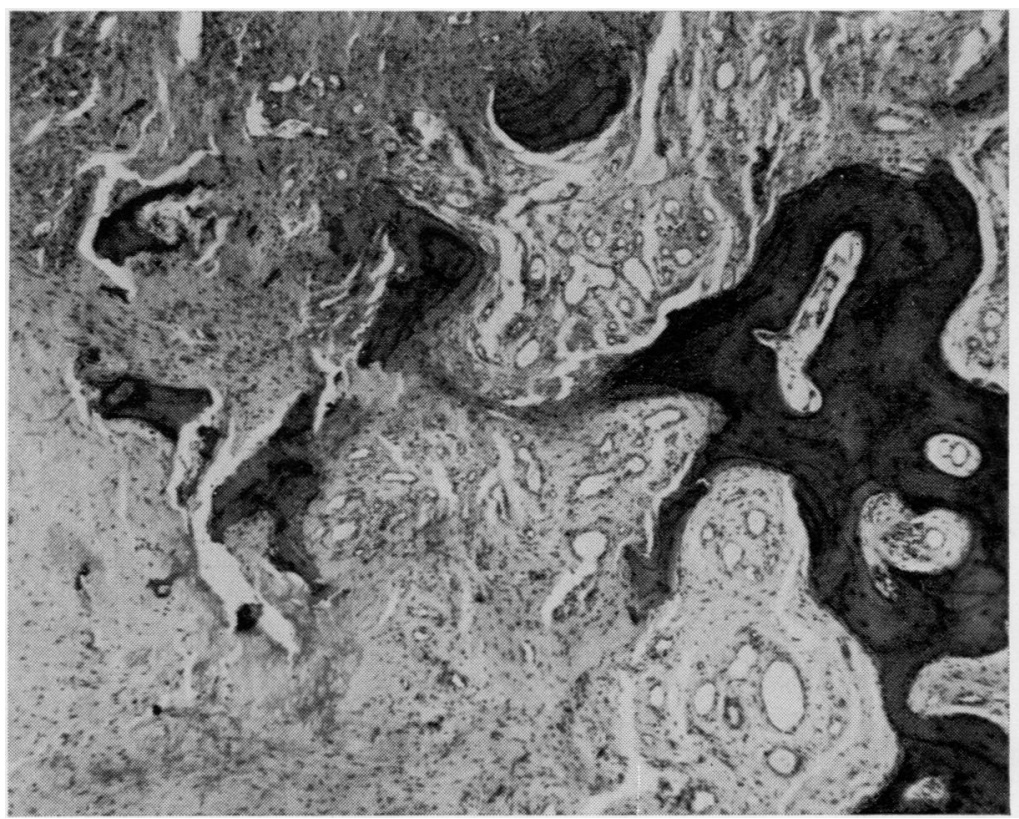


old haemorrhage and evidence at weak attempts at callus formation in the form of scattered foci of reactive fibrocartilage, cartilage, and rarely reactive (woven) bone in the fibrous tissue.

Zone $c$ (Figs 18, 19) consists of a narrow region of intense bone remodelling with lamellar trabecular sclerosis. The marrow spaces in this zone are oedematous and contain scattered perivascular collections of lymphocytes and plasma cells. This zone merges gradually with vertebral bone which is normal apart from some oedema and hypocellularity of the marrow.

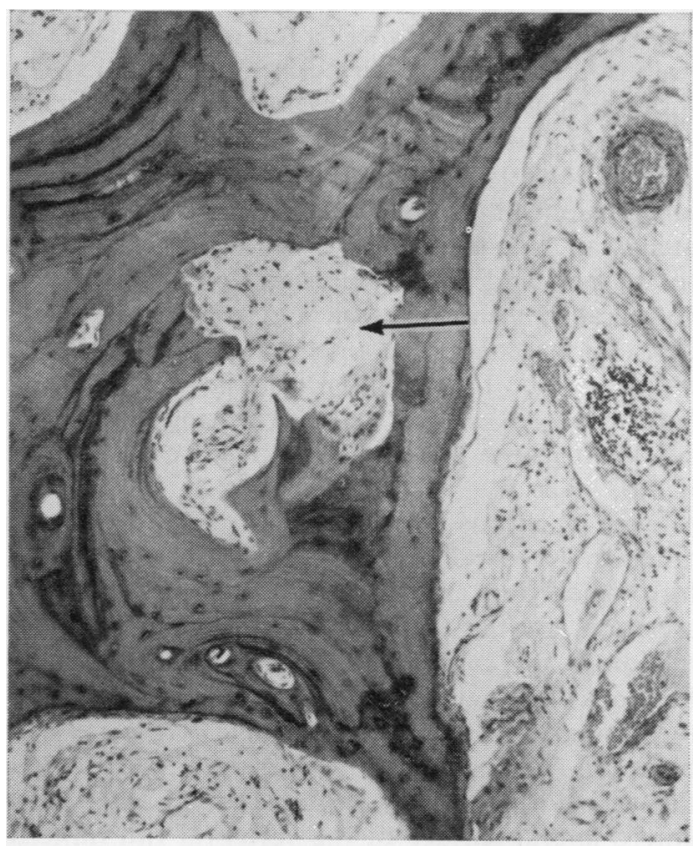

FIG. 18 Case 4. Type e lesion. Zone c Bone trabeculae, showing appositional sclerosis (upper left) and active osteoclastic resorption (arrow). Focal lymphocyte and plasma cell aggregates in oedematous marrow (centre right). Haematoxylin and eosin $\times 95$
UN-UNITED FRACTURES

In eight of thirteen cases of un-united fractures in patients without AS, small scanty aggregates of lymphocytes and plasma cells were seen in oedematous marrow neighbouring the fracture site (Fig. 19).

\section{Treatment}

The therapeutic measures required to relieve symptoms in each case are indicated in Table II. Patients with minor lesions and relatively mild symptoms were advised to modify their occupation and avoid flexion strains. Where this was impractical or unsuccessful, a spinal support was fitted. This was of the Milwaukee, Fisher, or modified Goldthwaite type. In three patients, all with severe (Type $e$ ) lesions, this was unsuccessful, and surgical treatment, involving spinal interbody fusion by bone-graft, was carried out. In one other patient (Case 8) surgical treatment was undertaken at the patient's request to correct thoracic kyphosis.

This therapeutic approach invariably resulted in relief of pain. Follow-up, with one exception, has not yet exceeded 3 years (Table II). Recurrence of symptoms and progression of radiographic changes have not been observed after effective immobilization. In two patients (Cases 1 and 5), the follow-up radiographs are suggestive of repair, although we have no histological confirmation of this. Radiographs of the patient followed up for 16 years (Case 2) showed unequivocal healing with massive osteophytes and bony sclerosis.

\section{Discussion}

In the present study patients with AS who presented with a history of localized back pain of relatively recent onset, made worse by movement and relieved by rest, have invariably been found to have a destructive lesion of a vertebral body corresponding to the painful region.

Although the ESR was often raised, as expected in AS, there was no evidence of a general

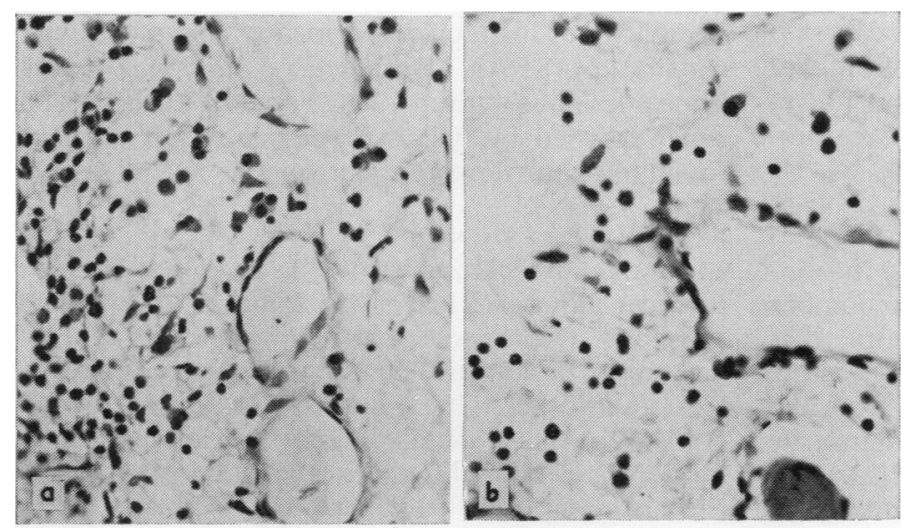

FIG. 19 Lymphocytic and plasma cell infiltration in oedematous marrow

(a) Destructive lesion (Case 4)

(b) Nonunited fracture of first phalanx of great toe after 12 months in plaster. Haematoxylin and eosin $\times 235$ Isolation of synovial fluid cells 
increase in disease activity concomitant with the change in symptoms. In contrast to patients without destructive lesions, all our patients were physically active at the time of onset of symptoms, and in some the onset clearly dated from a minor traumatic episode. The onset of pain was usually abrupt and there was invariably a delay of some months before the patient was seen in hospital. At this time local tenderness and pain could usually be elicited by direct pressure over the site of the lesion where there was sometimes a gibbus. These clinical features can be found in whole or in part in the case reports of Edström (1940), Jacqueline (1956), Coste and others (1963), Hansen and others (1967), Hicklin (1968), and Kanefield and others (1969). They constitute a syndrome sufficiently different from that of a spondylitic relapse to suggest that some other pathogenic factor is involved.

Although destructive lesions may be mistaken clinically for pyogenic or tuberculous osteomyelitis (Forestier and others, 1951; Romanus and Ydén, 1952; Pflüger, 1959), the problem of their pathogenesis centres on whether they are essentially part of the inflammatory process of AS or simply due to trauma.

\section{LOCALIZED LESIONS}

These may be seen in both ankylosed and unanklyosed spines (Dihlmann, 1968). As might be expected, clinical symptoms and signs were in general less pronounced than in patients with Type $e$ lesions. It is therefore possible that they may be overlooked, especially as some localized lesions can be detected only by tomography.

Coste and others (1963) and Strěda, (1964) have noted the radiological resemblance of some of these lesions to one or other form of discal herniation. Histological studies of localized lesions have not been reported. In one of our patients a localized lesion in an unankylosed lumbar spine was found by histological examination to be a discal hernia. Since, according to Schmorl and Junghanns (1959), discal herniation is common in non-spondylitic spines studied post mortem, it must be considered that a discal hernia may be a coincidental lesion. If, however, discal herniation is commoner in AS, and this has not at present been established, then there must be a predisposing cause. We would suggest that this is osteoporosis which, in the case referred to above, had produced focal bone loss of the subchondral plate, similar to that which we have found in nonspondylitic forms of osteoporosis. Since the lumbar spine in question was not ankylosed by bone, it is possible that in AS the lumbar spine (and possibly other zones) is susceptible to osteoporosis from the early stages of the disease. It could, of course, be argued that the discal herniation observed by us was the late result of a small destructive inflammatory lesion in the bone just beneath the subchondral plate. We think this unlikely, because studies of unankylosed lumbar spines in AS have shown no evidence of focal osteitis (Ball, 1971).

Discal herniation (in the sense of Schmorl and Junghanns, 1959) is restricted to the cartilaginous part of the vertebral end-plate. When herniation is situated at the periphery of the plate, the inner part of the rim may be involved, as was evident in one of the lesions studied by us. But discal herniation cannot account for Type $b$ lesions which produce cup-shaped defects in the discal surface of the vertebral rim where the avascular part of the annulus is attached. The Type $b$ lesions in the anterior vertebral rims of the kyphotic thoracic spine of one of our cases were histologically similar to those described by Schmorl and Junghanns (1959) in elderly non-spondylitic kyphotic individuals and attributed by them to the compressive forces generated by the kyphosis. Progressive kyphosis, according to Schmorl and Junghanns, leads to collapse of the vertebral rim and invasion and replacement of the disc by vascular fibrous tissue which ultimately ossifies. Since thoracic kyphosis is a characteristic feature of AS, it is hardly surprising that lesions similar to those of senile kyphosis are encountered in AS.

Type $b$ lesions may, however, also involve the anterior vertebral rim in the lumbar spine. No histological data are available on these lesions in this situation, but the assumption that they are primarily inflammatory can be questioned on two counts. Previous histological studies (Ball, 1971) indicate that the primary inflammatory process in the vertebral bodies in AS specifically involves the attachments of the vascularized outer annulus to the anterior or antero-lateral surface of the vertebral rim (anterior spondylitis). Radiologically this area seems to remain intact in Type $b$ lesions, which is not what one would expect if these were unusual extensions of anterior spondylitis. Secondly, if Type $b$ lesions are not severe forms of anterior spondylitis, it is difficult to see how they could be primarily inflammatory, as the part of the annulus involved is avascular and, as noted above, we find no histological evidence for a primary osteitis in AS. An alternative possibility is that a Type $b$ lesion is a traumatic collapse or avulsion of a rim weakened by the osteoporosis, which we have found in unankylosed lumbar spines.

\section{EXTENSIVE LESIONS}

In contrast to localized lesions, Type $e$ lesions appear to occur almost exclusively in spines with advanced ankylosis. Our histological findings in this type of destructive lesion are similar to those reported by Coste and others (1963) and Rivelis and Freiberger (1969), the most detailed reports available. These authors, however, differed in their interpretation of the histology, the former drawing attention to the 
inflammatory cell component, whereas the latter interpreted the pathology as a pseudarthrosis. We agree with Coste and others (1963) and with Hackenbroch (1967) that the inflammatory cell infiltration is of a minor order; but, since we find similar if less prominent infiltration in un-united fractures in nonspondylitics, the possibility cannot be excluded on pathological grounds that the inflammatory cell infiltration in destructive lesions is merely secondary to persistent and uncontrolled traumatic tissue damage at the disc-bone border. The associated bone destruction, the presence of minimal amounts of callus, evidence of old haemorrhage, and neighbouring bone sclerosis may indeed all be encountered in un-united fractures. Thus the histological evidence on which a primary inflammatory aetiology is entirely based is questionable.

The most important single piece of evidence supporting a traumatic aetiology is provided by the sequential radiographs of Kanefield and others (1969) which indicate that a destructive lesion may be the late result of an uncomplicated undisplaced fracture through an ankylosed segment. None of our patients was seen at the time of onset of the new symptoms so that we cannot confirm or refute this observation. However, in two of our five patients with severe lesions, there were discontinuities in the corresponding neural arch. These fractures could conceivably have been secondary to instability induced by a preexisting inflammatory disc lesion. On the other hand, Schmorl and Junghanns (1959) stated that fractures of the neural arch were invariably accompanied by damage to the disc which might not become apparent radiologically until some time after the initial trauma. Since our patients with extensive lesions invariably presented some months after the onset, it is possible that the fractures of the neural arch and the initiation of disc pathology were contemporaneous.

Severe lesions seem to occur mainly, if not exclusively, in patients with advanced spinal disease. From observations on two spines without destructive lesions (before and after maceration), we can say that in AS the extent of bony bridging in ankylosed regions may be variable - a feature noted by Aufdermaur (1957), and secondly that an individual segment may remain mobile when blocks of vertebrae above and below are ankylosed. Such mobile segments will be subject to abnormal stress. It would appear, therefore, that, during the natural evolution of spinal ankylosis, a situation may arise in which isolated segments, mobile or ankylosed, are especially susceptible to trauma. If severe destructive lesions are simply the late result of spinal trauma, then radiographs taken at the time of onset of symptoms should show evidence of isolated segmental instability with or without a fracture and no evidence of a destructive lesion. It is, indeed, a striking feature of the literature on the late complications of AS that surgeons seeing the patient immediately after a traumatic event describe fractures with or without dislocation and physicians seeing the patients only after an interval of a few months describe and debate destructive lesions.

\section{TREATMENT}

The management of these lesions has received little attention in the literature and the comments that have been made are based more on the individual author's views of the pathogenesis than on reported follow-up of cases. Louyot and others (1963) mentioned improvement after radiotherapy but there is little support for this from other sources. It is of interest that one of our patients was referred because the pain was not relieved by radiotherapy. We have treated our patients by immobilization on the assumption that destructive lesions are essentially traumatic. This has been successful without exception, rapid symptomatic relief being obtained in all cases. The beneficial effect of this policy of immobilization is of interest in view of the known deleterious effect of immobility on the symptoms of active spondylitis. The degree of immobilization required depended on the extent and instability of the lesion and the mode of life of the individual: in some a change of occupation was sufficient, in others some form of a spinal support was required, and in the most severe cases surgical fusion was necessary. In our limited follow up we have not so far observed recurrence of pain, and in one patient not treated surgically and with a follow up of 16 years healing with massive osteophyte formation has occurred.

\section{Summary}

(1) Seventeen patients with AS and various types of destructive lesions of the vertebral bodies have been studied.

(2) In the fifteen patients studied clinically, the lesion was characterized by a change in symptoms, the patient complaining of localized back pain exacerbated by movement and of some months' duration. All were manual workers.

(3) When first seen the lesions presented radiologically as either $(a)$ a localized defect in the vertebral rim or cartilaginous end-plate, or $(b)$ destruction of most of the disc-bone border. In one of the ten localized lesions and two of the five severe lesions, there was a fracture of the corresponding neural arch. Severe lesions were seen only in spines with ankylosis above and below the affected segment. Tomography was necessary to visualize some localized lesions.

(4) Lesions were studied histologically in six patients. Localized lesions in the cartilaginous end-plate in the lumbar region proved to be discal herniae. Rim lesions in the thoracic region resembled the early stages of senile kyphosis. Focal osteoporotic defects of 
the subchondral plate were observed in ankylosed and unankylosed spines and were considered to predispose the spine in Cases of AS to localized lesions. Severe lesions had many of the histological features of a pseudarthrosis and a simple traumatic aetiology could not be excluded histologically.

(5) Measures calculated to reduce spinal mobility, including surgical fixation, were invariably followed by rapid symptomatic relief.

\section{References}

ANDERSSON, O. (1937) Nord. Med. 14, 2000 (Röntgenbilden vid spondylarthritis ankylopoetica)

Aufdermaur, M. (1957) 'The Morbid Anatomy of Ankylosing Spondylitis.' Documenta Rheumatologica Geigy, No. 2

BaLl, J. (1971) Ann. rheum. Dis., 30, 213 (Enthesopathy of rheumatoid and ankylosing spondylitis)

Coste, F., Delbarre, F., Cayla, J., Massias, P., and Beaslay, E. (1963) Presse med., 71, 1013 (Spondylites destructives dans la spondylarthrite ankylosante)

Daneo, V., AND Di Vittorio, S. (1970) Rev. Rhum., 37, 155 (La spondylodiscite de la spondylarthrite ankylosante)

DinlmanN, W. (1968) 'Spondylitis Ankylopoietica-die Bechterewsche Krankheit.' Thieme, Stuttgart

EDSTRöM, G. (1940) Acta med. scand., 104, 396 (Is spondylarthritis ankylopoietica an independent disease or a rheumatic syndrome?)

Forestier, J., JACQUELINE, F., AND Rotès-QUÉrol, J. (1956) 'Ankylosing Spondylitis-Clinical Observations, Roentgenology, Pathological Anatomy, and Treatment,' trans. A. U. Desjardins. Thomas, Springfield, Ill.

Guest, C. M., AND JACOBSON, H. G. (1951) Amer. J. Roentgenol., 65, 760 (Pelvic and extrapelvic osteopathy in rheumatoid spondylitis. A clinical and roentgenographic study of ninety cases)

HACKeNBroch, M. H. (1967) Z. Orthop., 103, 23 (Umschriebene osteolytische Prozesse bei Spondylarthritis ankylopoetica)

Hansen, S. T., TAylor, T. K. F., Honet, J. C., AND Lewis, F. R. (1967) J. Trauma, 7, 827 (Fracture-dislocations of the ankylosed thoracic spine in rheumatoid spondylitis. Ankylosing spondylitis, Marie-Strümpell disease)

Hicklin, J. A. (1968) Ann. phys. Med., 9, 206 (Erosive vertebral disease in ankylosing spondylitis)

JACQUELINE, F. (1956) J. Radiol. Electrol., 37, 887 (Troubles de la structure osseuse et lésions destructives au cours de la spondylarthrite ankylosante)

- (1965) Rhumatologie, 17, 223 (Destructions du rachis antérieur lombo-dorsal au cours de la spondylarthrite ankylosante)

Kanefield, D. G., Mullins, B. P., Freehafer, A. A., Furey, J. G., Horenstein, S., and Chamberlin, W. B. (1969) J. Bone Jt Surg., 51A, 1369 (Destructive lesions of the spine in rheumatoid ankylosing spondylitis)

Louyot, P., Gaucher, A., Mathieu, J., AND Miquel, G. (1963) Rev. Rhum., 30, 263 (La spondylodiscite de la spondylarthrite ankylosante)

PflüGER, W. (1959) Tuberkulosearzt, 13, 414 (Spondylarthritis ankylopoietica und Spondylitis tuberculosa, eine seltene Kombination)

Rivelis, M., AND FreIBerGer, R. H. (1969) Radiology, 93, 251 (Vertebral destruction at unfused segments in late ankylosing spondylitis)

RomanUs, R., AND YDÉN, S. (1952) Acta orthop. scand., 22, 88 (Destructive and ossifying spondylitic changes in rheumatoid ankylosing spondylitis (Pelvo-spondylitis ossificans))

SCHMORL, G., AND JUNGHANNS, H. (1959) "The Human spine in Health and Disease", trans. S. P. Wilk and L. S. Goin from 'Die gesunde und die kranke Wirbelsäule in Röntgenbild und Klinik', 4th ed. (1957). Grune and Stratton, New York and London

SchULITZ, K.-P. (1968) Arch. Orthop. Unfall-Chir., 64, 116 (Destruktive Veränderungen an Wirbelkörpern bei der Spondylarthritis ankylopoietica)

- (1969) Med. Klin., 64, 593 (Spondylodiszitis bei Morbus Bechterew)

Seaman, W. B., AND Wells, J. (1961) Amer. J. Roentgenol., 86, 241 (Destructive lesions of the vertebral bodies in rheumatoid disease)

Serre, H., Simon, L., and Claustre, J. (1965) J. Radiol. Electrol., 46, 538 (Les lésions destructrices des disques et des corps vertébraux au cours de la spondylarthrite ankylosante)

StrěDA, A. (1964) Radiol. Diagn. (Berl.), 5, 43 (Inflammatory destructive changes in the spinal column in ankylosing spondylarthritis)

Wholey, M. H., Pugh, D. G., AND Bickel, W. H. (1960) Radiology, 74, 54 (Localized destructive lesions in rheumatoid spondylitis)

Wilkinson, M., AND Bywaters, E. G. L. (1958) Ann. rheum. Dis., 17, 209 (Clinical features and course of ankylosing spondylitis) 